\title{
Increased Respiratory Drive and Limited Adaptation to Loaded Breathing in Bronchopulmonary Dysplasia
}

\author{
JAY S. GREENSPAN, MARLA R. WOLFSON, ROBERT G. LOCKE, JULIAN L. ALLEN, AND \\ THOMAS H. SHAFFER \\ Departments of Pediatrics and Physiology, Temple University School of Medicine, Temple University Hospital, \\ Philadelphia, Pennsylvania 19140
}

\begin{abstract}
Ventilatory parameters and respiratory drive with and without an added acute resistive load were assessed in 11 healthy preterm infants and 11 infants with bronchopulmonary dysplasia (BPD). Lung mechanics (breathing frequency, tidal volume, minute ventilation, compliance, and resistance) were determined with esophageal manometry and pneumotachography. Respiratory drive was assessed by determining the airway pressure measured $100 \mathrm{~ms}$ after the onset of an inspiratory effort against an occlusion. Infants were studied at baseline and with an external inspiratory resistive load of $213.7 \mathrm{~cm}$ $\mathrm{H}_{2} \mathrm{O} / \mathrm{L} / \mathrm{s}$. Infants with $\mathrm{BPD}$ had similar breathing frequency, tidal volume, and minute ventilation, lower compliance, and greater resistance and airway pressure at $\mathbf{1 0 0}$ ms than healthy preterm infants at rest. With loading, healthy preterm infants demonstrated increased airway pressure at $100 \mathrm{~ms}$, whereas infants with BPD showed no change. Although the healthy preterm infants had decreased minute ventilation and tidal volume with loading, decreases in ventilation were greater in the infants with BPD. These data demonstrate that infants with BPD have responded to a chronic intrinsic load with increased drive. However, this may result in decreased ventilatory reserve and hence, a limited ability to adapt to acute pulmonary loads. (Pediatr Res 32: 356-359, 1992)
\end{abstract}

\section{Abbreviations}

BPD, bronchopulmonary dysplasia $\mathrm{C}_{\mathrm{L}}$, dynamic pulmonary compliance MV, minute ventilation

$P_{100}$, airway pressure at $100 \mathrm{~ms}$

$\mathbf{R}$, pulmonary resistance

$V_{T}$, tidal volume

The process of lung healing and repair in infants with BPD is very gradual and is associated with slow resolution of abnormalities in pulmonary function (1). This disability results in a prolonged requirement for respiratory support, increased work of breathing, and delayed growth and development (2). Nevertheless, many preterm infants with BPD progress clinically to weaning from ventilatory assistance and are eventually discharged from the hospital. To the extent that clinical improvement often proceeds without concomitant changes in pulmonary

Received February 13, 1992; accepted May 12, 1992.

Correspondence and reprint requests: Jay S. Greenspan, M.D., Department of Physiology, Temple University School of Medicine, 3410 N. Broad St., Philadelphia, PA 19140. function (3), much of the clinical success of these neonates must, therefore, be due to the neonates' ability to adapt to the respiratory load offered by their abnormal pulmonary function.

A component of the respiratory adaptation is the infant's respiratory center output. Changes in the respiratory center output can be assessed by measuring the mouth pressure generated $0.1 \mathrm{~s}$ after an airway occlusion at end expiration $\left(\mathrm{P}_{100}\right)(4-$ 6). The determination of the preterm neonate's respiratory center compensation for the chronic intrinsic respiratory load of BPD would help to clarify the apparent dichotomy in clinical and lung function improvement.

It has been reported that healthy preterm infants respond to the application of an acute respiratory load with an immediate decrease in MV and oxygen consumption with minimal disturbances in arterial blood gas tensions $(4,7,8)$. However, the ability of healthy newborns to change their respiratory drive in response to resistive loads remains unclear. Duara et al. (4) observed no change in $\mathrm{P}_{100}$ in preterm human infants after experimental loading, whereas other studies have demonstrated increased occlusion pressures during loading in 48-h-old monkeys and preterm infants $(9,10)$. Changes in $\mathrm{P}_{100}$ for infants with BPD after experimental loading have not been explored.

Healthy preterm infants and infants with BPD are frequently required to adapt to added pulmonary loads such as feedingrelated stress, acute illness, transient upper airway obstruction during neck flexion, or iatrogenic interventions (11-15). The response of the infant to these acute stressors would depend on the relationship between the ventilatory load and the compensatory mechanisms available. A successful adaptation to intrinsic or extrinsic pulmonary stressors can be defined as a maintenance of normal MV and/or arterial blood gas tensions. We hypothesized that infants with BPD have a different respiratory output at rest than do healthy preterm infants because of different chronic intrinsic pulmonary loads, and they may respond differently to additional acute resistive loads. The purpose of this study was to assess the $P_{100}$ and ventilatory parameters at rest and in response to an acute added resistive load in healthy preterm infants and infants with BPD.

\section{MATERIALS AND METHODS}

A total of 22 infants were enrolled and studied in two groups. Group 1 consisted of 11 healthy preterm infants (mean \pm SD birth weight $1.39 \pm 0.38 \mathrm{~kg}$, gestational age $30.5 \pm 2 \mathrm{wk}$, study weight $1.44 \pm 0.31 \mathrm{~kg}$, study postconceptional age $32 \pm 2 \mathrm{wk}$ ), and group 2 consisted of 11 preterm infants with BPD (mean \pm SD birth weight $0.74 \pm 0.14 \mathrm{~kg}$, gestational age $26 \pm 2 \mathrm{wk}$, study weight $1.35 \pm 0.3 \mathrm{~kg}$, study postconceptional age $33 \pm 3 \mathrm{wk}$ ). BPD was defined as a requirement for supplemental oxygen greater than $25 \%$ inspired oxygen concentration at $28 \mathrm{~d}$ of life. All infants were free of intercurrent illness, older than $1 \mathrm{wk}$ of 
age, breathing room air, and deemed stable by the attending neonatologist. The protocol was approved by the institutional review board and informed parental consent was obtained. Infants were studied while unsedated, in the supine resting position, breathing room air. To minimize the confounding influences of sleep state on measured parameters, infants were studied in quiet sleep as determined by clinical criteria (16). They were continuously monitored for heart and respiratory rates (Spacelabs monitor, Redmond, WA) and oxyhemoglobin saturation (Nellcor Pulse Oximeter, Hayward, CA).

Assessment of lung mechanics. Signals of airflow, $\mathrm{V}_{\mathrm{\Upsilon}}(\mathrm{mL} / \mathrm{kg})$, and transpulmonary pressure were simultaneously recorded during quiet breathing. Airflow was measured with pneumotachometry and the signal was digitally integrated to determine $\mathrm{V}_{\mathrm{T}}$; $\mathrm{MV}(\mathrm{mL} / \mathrm{kg} / \mathrm{min}$ ) and timing ratio (inspiratory time/total time) were then calculated. Intrapleural pressure changes were assessed with esophageal manometry, and mouth pressure was measured on the side port of the pneumotachometer. Transpulmonary pressure was determined as the difference between mouth pressure and esophageal pressure. Balloon accuracy was ensured by careful scrutiny of the on-line pressure tracing and the occlusion technique (17). Signals were collected over a 60 - to 120 -s period and stored for analysis (PEDS, Medical Associated Services, Hatfield, PA). Calculation of $\mathrm{C}_{\mathrm{L}}\left(\mathrm{mL} / \mathrm{cm} \mathrm{H} \mathrm{H}_{2} \mathrm{O} / \mathrm{kg}\right)$ and $\mathrm{R}(\mathrm{cm}$ $\mathrm{H}_{2} \mathrm{O} / \mathrm{L} / \mathrm{s}$ ) was determined with the least mean square analysis (18).

Application of external inspiratory resistive loads. A one-way nonrebreathing valve was attached to the pneumotachograph, attached to the face mask, and placed on the infant's face, ensuring a good seal. An external inspiratory flow-resistive load of $200 \mathrm{~cm} \mathrm{H} \mathrm{H}_{2} \mathrm{O} / \mathrm{L} / \mathrm{s}$ (Hans Rudolph Inc., Kansas City, MO; linear overflow rates of $0-0.1 \mathrm{~L} / \mathrm{s}$ ) was applied by attaching the load to the inspiratory port of a nonrebreathing valve and pneumotachograph ( $\mathrm{R} 13.7 \mathrm{~cm} \mathrm{H} \mathrm{H}_{2} \mathrm{O} / \mathrm{L} / \mathrm{s}$, dead space $2.5 \mathrm{~mL}$ ), creating a total resistive load of $213.7 \mathrm{~cm} \mathrm{H} \mathrm{O} / \mathrm{L} / \mathrm{s}$. The load was applied for $30 \mathrm{~s}$ before data recording and remained in place for a maximum of $3 \mathrm{~min}$. In addition to vital signs and transcutaneous pulse oximetry, the infants were continuously monitored for MV through pneumotachography.

Measurement of $P_{100}$. An occlusion valve with a manual trigger was placed on the inspiratory port of the nonrebreathing valve, which could be occluded while the infant was freely exhaling. Airway pressures generated during an occluded inspiration were monitored at the mouth pressure port of the pneumotachograph. As previously described (7), airway pressure was measured 100 ms after the onset of the subsequent inspiratory effort $\left(\mathrm{P}_{100}\right)$. The occluder released $0.25-0.3 \mathrm{~s}$ after inspiration was initiated, to permit further tidal breathing. Samples were excluded if breathing was irregular before the occlusion or if leakage was observed (loss of volume as read by the pneumotachograph). A mean of three acceptable occlusions was considered to be the infant's $P_{100}$ at that time.

Protocol. After baseline pulmonary mechanics were determined, the infant's $P_{100}, V_{T}$, breathing frequency, and $M V$ were measured $30 \mathrm{~s}$ after the application of the resistive load and in the unloaded state. The order of testing (loaded or unloaded) was randomized. In addition, five of these infants (three with BPD and two healthy preterm infants) were tested with the resistive load and pneumotachograph placed for $5 \mathrm{~min}$, and a probe for end-tidal $\mathrm{CO}_{2}$ monitoring (Nellcor N1000/N2500 endtidal $\mathrm{CO}_{2}$ ) was placed under the face mask.

Statistical analysis. Statistical differences in $\mathrm{MV}$ and $\mathrm{P}_{100}$ were determined as a function of infant condition (preterm infants and infants with BPD) and loaded with a two-factor analysis of variance. Statistical differences were further evaluated by Tukey post hoc testing. Statistical significance was accepted at the $p<$ 0.05 level.

\section{RESULTS}

The infants tolerated the procedure well, without arousal or a change in heart rate or transcutaneous pulse oximetry. The baseline pulse oximetry was $99 \pm 1 \%$ (SD) for the healthy preterms and $98 \pm 2 \%$ (SD) for the infants with BPD, which remained stable during loading. The five infants studied for changes in end-tidal $\mathrm{CO}_{2}$ had no change in $\mathrm{CO}_{2}$ with a 5 -min resistive load application. There were no significant differences between the groups (healthy preterm infants and infants with BPD) in infant weight or postconceptional age at the time of study. Tables 1 and 2 summarize the pulmonary function at baseline for the 11 healthy preterm infants (Table 1) and the 11 infants with BPD (Table 2). There was wide variability in $C_{L}$ and $R$ in infants with BPD, with mean values of $C_{L}, R$, and $P_{100}$ differing significantly from those of healthy preterm infants.

Typical tracings of airway pressure, airflow, and volume before and during airway occlusion for a healthy $1.51-\mathrm{kg}$ preterm infant are shown in Figure 1 (left panel, unloaded; right panel, with an added resistive load). The mean value for $V_{T}$ in this study for the loaded condition decreased from $9.8 \mathrm{~mL}(6.5 \mathrm{~mL} / \mathrm{kg}$ ) (unloaded) to $7.4 \mathrm{~mL}(4.9 \mathrm{~mL} / \mathrm{kg})$. The infant's breathing frequency of 65 breaths $/ \mathrm{min}$ at baseline increased to 71 breaths $/ \mathrm{min}$ with loading, resulting in a decreased $\mathrm{MV}$ with the load $(423 \mathrm{~mL} /$ $\mathrm{min} / \mathrm{kg}$ at baseline to $348 \mathrm{~mL} / \mathrm{kg} / \mathrm{min}$ with a load). Mean $\mathrm{P}_{100}$

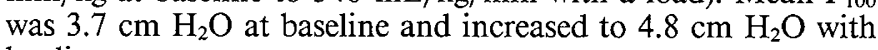
loading.

A similar tracing for a $1.1-\mathrm{kg}$ infant with BPD is displayed in Figure 2. The mean value for $V_{T}$ decreased from $7.8 \mathrm{~mL}(7.1$ $\mathrm{mL} / \mathrm{kg}$ ) at baseline to $4.9 \mathrm{~mL}$ with loading. The respiratory rate decreased from 61 breaths/min at baseline to 55 breaths $/ \mathrm{min}$

Table 1. Baseline pulmonary function profile: healthy preterm infants

\begin{tabular}{ccccccc}
\hline No. & $\mathrm{F}^{*}$ & $\mathrm{~V}_{\mathrm{T}}$ & $\mathrm{MV}$ & $\mathrm{C}_{\mathrm{L}}$ & $\mathrm{R}$ & $\mathrm{P}_{100}$ \\
\hline 1 & 69 & 5.9 & 406 & 1.63 & 59 & 2.3 \\
2 & 67 & 5.8 & 380 & 1.22 & 80 & 4.0 \\
3 & 56 & 7.3 & 410 & 2.07 & 23 & 4.2 \\
4 & 64 & 5.3 & 337 & 2.29 & 40 & 2.1 \\
5 & 72 & 4.1 & 295 & 1.04 & 42 & 4.8 \\
6 & 77 & 7.5 & 591 & 1.55 & 53 & 4.2 \\
7 & 70 & 5.9 & 410 & 2.22 & 11 & 3.8 \\
8 & 72 & 7.8 & 556 & 2.58 & 29 & 3.6 \\
9 & 60 & 7.8 & 456 & 2.10 & 29 & 2.8 \\
10 & 72 & 7.5 & 530 & 2.75 & 13 & 4.5 \\
11 & 62 & 5.6 & 348 & 2.15 & 26 & 2.9 \\
Mean & 67 & 6.4 & 429 & 1.79 & 35 & 3.6 \\
\pm SD & 2 & 0.5 & 29 & 0.2 & 7 & 0.3 \\
\hline
\end{tabular}

* Breathing frequency.

Table 2. Baseline pulmonary function profile: infants with BPD

\begin{tabular}{crrrrrl}
\hline No. & $\mathrm{F}^{*}$ & $\mathrm{~V}_{\mathrm{T}}$ & $\mathrm{MV}$ & $\mathrm{C}_{\mathrm{L}}$ & $\mathrm{R}$ & $\mathrm{P}_{100}$ \\
\hline 1 & 51 & 5.0 & 252 & 1.74 & 111 & 6.5 \\
2 & 79 & 5.9 & 457 & 0.99 & 85 & 4.5 \\
3 & 51 & 4.6 & 232 & 0.40 & 268 & 4.6 \\
4 & 61 & 4.7 & 288 & 1.40 & 215 & 4.6 \\
5 & 52 & 6.3 & 335 & 1.70 & 138 & 7.6 \\
6 & 72 & 8.5 & 620 & 0.67 & 61 & 6.1 \\
7 & 43 & 10.1 & 446 & 0.61 & 166 & 5.8 \\
8 & 86 & 4.5 & 392 & 0.52 & 80 & 7.6 \\
9 & 83 & 5.2 & 432 & 1.42 & 41 & 4.7 \\
10 & 36 & 7.8 & 269 & 1.24 & 170 & 5.0 \\
11 & 81 & 7.5 & 605 & 0.83 & 55 & 4.2 \\
Mean & 63 & 6.4 & 394 & $1.05 \dagger$ & $126 \dagger$ & $5.6 \dagger$ \\
\pm SEM & 5 & 0.4 & 40 & 0.14 & 22 & 0.3 \\
\hline
\end{tabular}

* Breathing frequency.

$\dagger$ Value significantly differs from healthy preterm, $p<0.05$. 


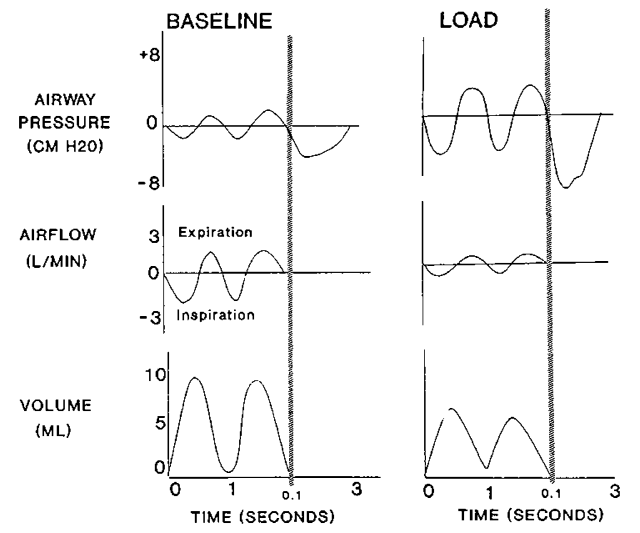

Fig. 1. Change in airway pressure, airflow, and volume several breaths before and at airway occlusion in a healthy preterm infant without (left panel) and with (right panel) added resistive load. $\mathrm{P}_{100}$ was measured 100 $\mathrm{ms}$ after inspiration was initiated during occlusion.
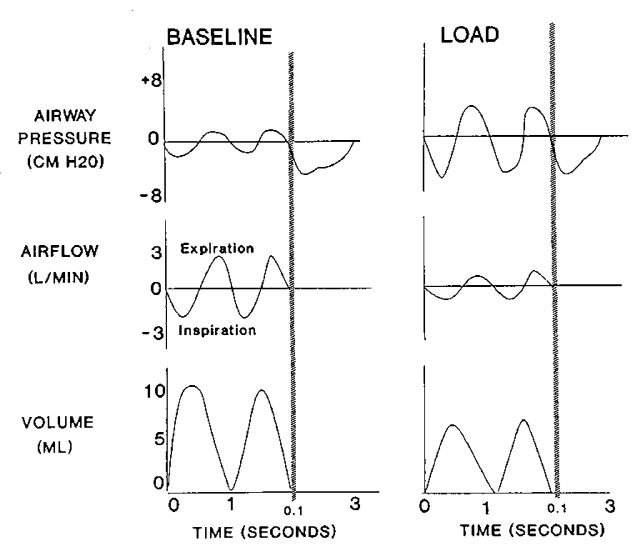

Fig. 2. Change in airway pressure, airflow, and volume several breaths before and at airway occlusion in an infant with BPD without (left panel) and with (right panel) added resistive load. $\mathrm{P}_{100}$ was measured $100 \mathrm{~ms}$ after inspiration was initiated during occlusion.

with a load, resulting in a decreased $\mathrm{MV}$ with loading (433 to $270 \mathrm{~mL} / \mathrm{kg} / \mathrm{min}$ ). The mean baseline $\mathrm{P}_{100}$ of $5.1 \mathrm{~cm} \mathrm{H}_{2} \mathrm{O}$ decreased to $3.4 \mathrm{~cm} \mathrm{H}_{2} \mathrm{O}$ with loading.

The mean pulmonary response to resistive loading for healthy preterm infants and infants with BPD is summarized in Table 3. Although both groups demonstrated decreases in $V_{T}$ and $M V$ with loading, the percentage of decrease in $\mathrm{MV}$ from baseline was greater in the infants with BPD. Timing ratios trended higher with loading in both groups, but they failed to achieve statistical significance ( $p=0.17$ for healthy preterm infants; $p=0.08$ for infants with BPD). All healthy preterm infants demonstrated an increase in $P_{100}$ with loading, resulting in a significant increase in mean $P_{100}$. In contrast, only two of the infants with BPD demonstrated an increase in $\mathrm{P}_{100}$, resulting in no significant difference in $\mathrm{P}_{100}$ between baseline and loaded conditions.

\section{DISCUSSION}

The pulmonary morbidity of BPD is characterized by airway and lung parenchyma abnormalities, which result in increased resistance to airflow $(1,2)$. This represents a chronic respiratory load, often resulting in respiratory insufficiency or failure. Recovery from this process requires either lung healing and growth or adaptation to the load. Although improvement in lung function does occur, this is often a slow process in infants with BPD (1). Clinical improvement, as evidenced by decreasing respiratory support requirements and eventual nursery discharge, may proceed without changes in pulmonary mechanics (3); therefore, other mechanisms such as adaptation to the resistive loads may play a significant role in clinical improvement.

In the present study, ventilatory and occlusion pressure $\left(\mathrm{P}_{100}\right)$ responses were determined in infants with BPD and compared with those in healthy preterm infants of a similar weight and postconceptional age. The infants with BPD had normal MV at baseline despite demonstrating a greater $\mathrm{R}(260 \%)$ than healthy infants. Moreover, infants with BPD demonstrated a greater $P_{100}$ at rest than did the healthy preterm infants. The value for $P_{100}$ did not correlate with mechanics measurements at baseline within groups. This suggests that preterm infants compensate for a chronic intrinsic load, in part, by increasing their respiratory drive. However, there does not appear to be a direct relationship between the degree of pulmonary compromise and the level of drive. Therefore, the etiology of the increased drive is multifactorial and, in addition to pulmonary mechanics, may relate to other parameters of pulmonary function of characteristics of individual infants.

When the infants with BPD were exposed to an acute resistive load, they failed to increase their $\mathrm{P}_{100} ; \mathrm{V}_{\mathrm{T}}$ and $\mathrm{MV}$ fell. This contrasts with the healthy preterm infants, who significantly increased $P_{100}$ and had an attenuated decrease in MV.

Previous studies have shown that healthy preterm infants compensate for an added acute resistive load to maintain eucapnia (7-9). In the present study, the healthy preterm infants demonstrated an increase in respiratory drive when loaded, yet MV was not supported. Similar results are obtained when 48 -hold monkeys are loaded (9), and Boychuk et al. (10) demonstrated increased inspiratory time and peak nasal pressures with airway occlusion in preterm infants. Duara et al. (4) demonstrated similar changes in $\mathrm{MV}$ and $\mathrm{PCO}_{2}$, but they found nonsignificant increases in $\mathrm{P}_{100}$ with experimental loading in preterm infants. Reasons for this discrepancy may be related to the smaller resistive load $\left(100 \mathrm{~cm} \mathrm{H}_{2} \mathrm{O} / \mathrm{L} / \mathrm{s}\right)$ or the smaller numbers of infants studied $(n=5)$. Previous investigators have found increases in timing ratios (inspiratory time/total time) when healthy infants are given a resistive load $(7,8)$. Although similar values are seen in the present study, values failed to achieve significance.

In contrast to the healthy preterm infants, the infants with BPD failed to increase their respiratory drive when given an additional acute resistive load. This was also accompanied by a greater fall in MV than seen in the loaded healthy preterm infants. This is particularly noteworthy in light of the marked

Table 3. Response to resistive loading*

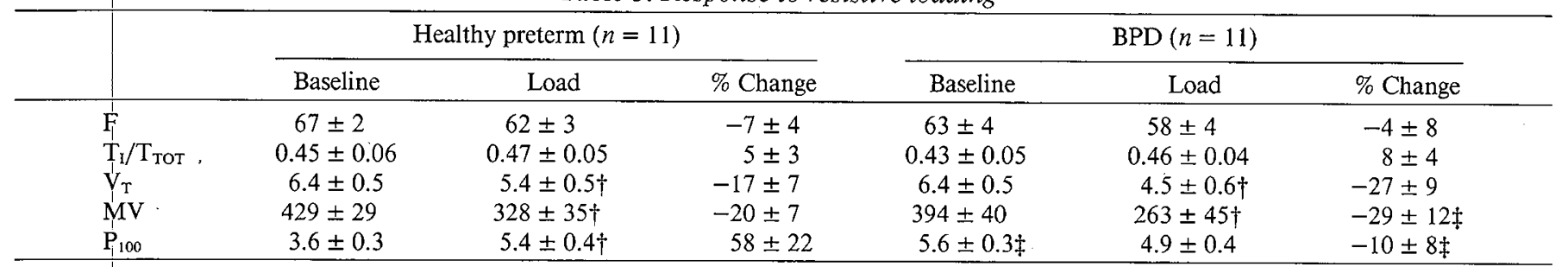

* Values are mean \pm SEM. $\mathrm{F}$, breathing frequency; $\mathrm{T}_{\mathrm{r}} / \mathrm{T}_{\mathrm{TOT}}$, inspiratory time/total time.

$\dagger$ Value significantly differs from baseline, $p<0.05$.

$\$$ Value significantly differs from healthy preterm, $p<0.05$. 
differences in percentage of increase in resistive load from baseline $510 \%$ increase in $\mathrm{R}$ for the healthy preterm infants versus $70 \%$ increase in infants with $\mathrm{BPD}$ ). A rising $\mathrm{PCO}_{2}$ was not observed in the infants with BPD, possibly because of the short duration of the load or because of metabolic compensation (9). Unlike the $\mathrm{P}_{100}$, the timing ratio response to loading appears to be similar in healthy infants and those with BPD.

The etiology of the difference in response to acute resistive loads in infants with BPD from that of healthy infants is unclear. One possible explanation is that the infants with BPD are operating at near-maximal drive when unloaded and are unable to defend against additional acute resistive loads. These infants are known to develop respiratory failure with minimal stress, supporting the concept of a low reserve to adapt to increased loads (2). Another possibility is that the infants with BPD have developed other compensatory mechanisms. Although their respiratory timing appears to be similar to that of healthy preterm infants, infants with BPD exhibit different breathing strategies, respiratory muscle synchrony, metabolic rate, and energy balance at rest from those of healthy preterm infants $(19,20)$, suggesting the capability for compensating differently to acute events.

The infants with BPD in this study have a chronic resistive load that is compensated to maintain normal ventilation and gas exchange. One of the strategies used by these infants is to increase the respiratory drive $\left(\mathrm{P}_{100}\right.$ increased by $\left.56 \%\right)$. This results in greater work of breathing and a greater oxygen consumption than are seen in healthy infants (19). The neonate's strategy for adapting to chronic loads, therefore, differs from the compensation for acute resistive loads.

The mouth occlusion pressure generated $0.1 \mathrm{~s}$ after an airway occlusion at end expiration has been used in adults and children to assess neural drive (4-6). The $\mathrm{P}_{100}$ changes with age, reflecting postnatal development of neural drive; occlusion pressures are greater in children than in adults (5). The $\mathrm{P}_{100}$ is also dependent on the performance of the respiratory muscles $(6,21)$, which can differ in infants with BPD versus healthy preterm infants (20). Furthermore, changes in lung mechanics, sleep state, or respiratory muscle positioning could alter driving pressures by changing the respiratory muscle's mechanical advantage (22-24). These factors may have contributed to the greater $P_{100}$ values seen in the infants with BPD.

The change in occlusion pressures in response to resistive loading is also dependent on postnatal age. Laframboise et al. (9) found that 48-h-old newborn monkeys had smaller increases in $\mathrm{P}_{100}$ than did 24-d-old monkeys when loaded. In the present study, this possible complicating factor was minimized by selecting infants who were 1 wk of age or older, and of similar postconceptional age. More importantly, age-related increases in $\mathrm{P}_{100}$ in response to loading would have been more prevalent in the infants with BPD, thereby making the fall observed in $P_{100}$ in these infants more significant.

In summary, this study has shown that one strategic approach for ventilatory compensation to the chronic intrinsic pulmonary load experienced by infants with BPD appears to be an increase in respiratory drive. This adaptation may account for clinical improvement despite slow lung healing and repair. Healthy preterm infants have lower respiratory drive at rest than infants with BPD, but they can respond to an additional acute resistive load by increasing drive. In contrast, infants with BPD do not demonstrate increased drive with acute loading, which results in a greater drop in MV than in healthy preterm infants. This suggests that infants with BPD have less ventilatory reserve and, hence, may be less able to compensate successfully for acute pulmonary stresses.

Acknowledgment. The authors thank the staff members of the Temple University Hospital Intensive Care Nursery for their support.

\section{REFERENCES}

1. Gerhardt T, Hehre D, Feller R, Reifenberg L, Bancalari E 1987 Serial determination of pulmonary function in infants with chronic lung disease. $J$ Pediatr 110:448-456

2. O'Brodovich HM, Mellins RB 1985 Bronchopulmonary dysplasia: unresolved neonatal acute lung injury. Am Rev Respir Dis 132:694-709

3. Greenspan JS, Abbasi S, Bhutani VK 1988 Sequential changes in pulmonary mechanics in the very low birth weight ( $\leq 1000$ grams) infants. J Pediatr 113:732-737

4. Duara S, Abbasi S, Shaffer TH, Fox WW 1985 Preterm infants: ventilation and $\mathrm{P}_{100}$ changes in $\mathrm{CO}_{2}$ and inspiratory resistive loading. J Appl Physiol 58:1982-1987

5. Gaultier C, Perret L, Boule M, Buvry A, Girard F 1981 Occlusion pressure and breathing pattern in healthy children. Respir Physiol 46:71-80

6. Whitelaw WA, Derenne JP, Milic-Emili J 1975 Occlusion pressure as a measure of respiratory center output in conscious man. Respir Physiol 23:181-199

7. Abbasi S, Duara S, Shaffer TH, Fox WW 1984 Effect of external inspiratory loading on ventilation of premature infants. Pediatr Res 18:150-154

8. Duara S, Neto GS, Gerhardt T, Suguihara C, Bancalari E 1991 Metabolic and respiratory effects of flow-resistive loading in preterm infants. J Appl Physiol 70:895-899

9. Laframboise WA, Standaert TA, Guthrie RD, Woodrum DE 1987 Developmental changes in ventilatory response of the newborn to added airway resistance. Am Rev Respir Dis 136:1075-1083

10. Boychuk RB, Seshia MMK, Rigatto H 1977 The immediate ventilatory response to added inspiratory elastic and resistive loads in preterm infants. Pediatr Res 11:276-279

11. Greenspan JS, Wolfson MR, Holt WJ, Shaffer TH 1990 Neonatal gastric intubation: differential respiratory effects between nasogastric and orogastric tubes. Pediatr Pulmonol 8:254-258

12. Martin RJ, Miller MJ, Carlo WA 1986 Pathogenesis of apnea in preterm infants. J Pediatr 109:733-741

13. Shivpuri CR, Martin RJ, Carlo WA, Fanaroff AA 1983 Decreased ventilation in preterm infants during oral feeding. J Pediatr 103:285

14. Thach BT, Stark A 1979 Spontaneous neck flexion and airway obstruction during apneic spells in preterm infants. J Pediatr 94:275-281

15. Greenspan JS, Wolfson MR, Shaffer TH 1991 Airway responsiveness to low inspired gas temperature in preterm neonates. J Pediatr 118:443-445

16. Shulte FJ 1981 Developmental neurophysiology. In: Davis J, Dobbins J, (eds). The Scientific Foundations of Pediatrics. University Park Press, Baltimore, pp 785-789

17. Beardsmore CS, Helms P, Stocks J, Hatch DJ, Silverman M 1980 Improved esophageal-balloon technique for use in infants. J Appl Physiol 49:735-742

18. Bhutani VK, Sivieri EM, Abbasi S, Shaffer T 1988 Evaluation of neonatal pulmonary mechanics and energetics: a two factor least mean square analysis. Pediatr Pulmonol 4:150-158

19. Yeh TF, McClenan DA, Ajayi A, Plides R 1989 Metabolic rate and energy balance in infants with bronchopulmonary dysplasia. J Pediatr 114:448-451

20. Allen JL, Greenspan JS, Deoras KS, Keklikian E, Wolfson MR, Shaffer TH 1991 Interaction between chest wall motion and lung mechanics in normal infants and infant with bronchopulmonary dysplasia. Pediatr Pulmonol 11:37-43

21. Carlo WA, Miller MJ, Martin RJ 1985 Differential response of respiratory muscles to airway occlusion in infants. J Appl Physiol 59:847-852

22. Allen JL, McDowell K, Wolfson MR, Shaffer TH 1990 Thoracoabdominal asynchrony in infants with airflow obstruction. Am Rev Respir Dis 141:337342

23. Wolfson MR, Greenspan JS, Deoras KS, Allen JL, Shaffer TH 1992 Effect of position on the mechanical interaction between the rib cage and abdomen in preterm infants. J Appl Physiol 72:1032-1038

24. Knill R, Andrews W, Bryan AC, Bryan MH 1976 Respiratory load compensation in infants. J Appl Physiol 40:357-361 